\title{
Significance of Fermented Food in Nutrition and Food Science
}

\author{
M. N. Hasan ${ }^{1, *}$, M. Z. Sultan' ${ }^{2}$ and M. Mar-E-Um \\ ${ }^{1}$ Institute of Nutrition and Food Science, University of Dhaka, Dhaka-1000, Bangladesh \\ ${ }^{2}$ Centre for Advanced Research in Sciences, University of Dhaka, Dhaka-1000, Bangladesh \\ ${ }^{3}$ Food and Nutrition Department, Khulna City Corporation Women's College, Khulna University, \\ Khulna, Bangladesh
}

Received 8 October 2013, accepted in final revised form 2 April 2014

\begin{abstract}
Fermenting foods can make poorly digested, reactive foods into health giving foods. The process of fermentation destroys many of the harmful microorganisms and chemicals in foods and adds beneficial bacteria. These bacteria produce new enzymes to assist in the digestion. Foods that benefit from fermentation are soy products, dairy products, grains, and some vegetables. The beneficial effect of fermented food which contains probiotic organism consumption includes: improving intestinal tract health, enhancing the immune system, synthesizing and enhancing the bioavailability of nutrients, reducing symptoms of lactose intolerance, decreasing the prevalence of allergy in susceptible individuals, and reducing risk of certain cancers. This article provides an overview of the different starter cultures and health benefits of fermented food products, which can be derived by the consumers through their regular intake.
\end{abstract}

Keywords: Fermentation; Fermented food; Starter cultures; Probiotics; Nutritional benefits.

๑) 2014 JSR Publications. ISSN: 2070-0237 (Print); 2070-0245 (Online). All rights reserved.

doi: http://dx.doi.org/10.3329/jsr.v6i2.16530 J. Sci. Res. 6 (2), 373-386 (2014)

\section{Introduction}

Fermentations occur when microorganisms consume susceptible organic substrates as part of their own metabolic processes. Such interactions are fundamental to the decomposition of natural materials, and to the ultimate return of chemical elements to the soil and air without which life could not be sustained. Currently the term fermentation refers to breakdown of carbohydrate and carbohydrate like materials under either anaerobic or aerobic conditions. The term fermented foods is used to describe a special class of food products characterized by various kinds of carbohydrate breakdown in the presence of probiotic microorganisms; but seldom is carbohydrate the only constituent acted upon [1].

\footnotetext{
*Corresponding author: mnh_rony@yahoo.com
} 
Most fermented foods contain a complex mixture of carbohydrates, proteins, fats, and so on; undergoing modification simultaneously, or in some sequence, under the action of a variety of microorganisms and enzymes. In addition to the roles of fermentation in preservation and providing variety to the diet, there are further important consequences of fermentation. Several of the end products of food fermentation, particularly acids and alcohols, are inhibitory to the common pathogenic microorganisms that may find their way into foods, e.g. inability of Clostridium botulinum to grow and produce toxin at $\mathrm{pH}$ values of $\leq 4.6$. When microorganisms ferment food constituents, they yield energy in the process and increase in numbers. To the extent that food constituents are oxidized, their remaining energy potential for human decreases [1]. Compounds that are completely oxidized by fermentation to such end products as $\mathrm{CO}_{2}$ and water retain no further energy value. Some of the beneficial effect of fermented food which contains probiotic organism consumption include: (i) improving intestinal tract health; (ii) enhancing the immune system, synthesizing and enhancing the bioavailability of nutrients; (iii) reducing symptoms of lactose intolerance, decreasing the prevalence of allergy in susceptible individuals; and (iv) reducing risk of certain cancers. The mechanisms by which probiotics exert their effects are largely unknown, but may involve modifying gut $\mathrm{pH}$, antagonizing pathogens through production of antimicrobial compounds, competing for pathogen binding and receptor sites as well as for available nutrients and growth factors, stimulating immunomodulatory cells, and producing lactase. The fermenting organisms include LAB (Lactic acid bacteria) such as Leuconostoc, Streptococcus, Lactobacillus, Enterococcus, Aerococcus and Pediococcus spp. [2, 3]. The yeasts isolated are mainly of the species Saccharomyces, Kluyeromyces and Debaryomyces [4]. Moulds have been used mainly in milk and cheese fermentation and include Penicillium, Mucor, Geotrichium, and Rhizopus species [5, 6]. Some of the microorganisms isolated from fermented food are, however, yet to be identified. In all the foods and beverages examined, LAB is the dominant microorganisms, and therefore, lactic acid fermentation is considered as the major contributor to the beneficial characteristics observed in fermented foods. The numerous fermented food products in Asia can be categorized into five groups: (1) fermented soybean products, (2) fermented fish products, (3) fermented vegetable products, (4) fermented bread and porridges, and (5) alcoholic beverages. Probiotics are involved in all of these fermentations to a varying extent, having either positive or negative effects on the eventual product. Nutrition is known to influence the heath and can thereby modulate resistance to infection. So, our objective of this study is to assess the influence of a fermented food in health of the volunteers.

\section{Health Benefit of Fermented Food}

\subsection{Probiotics}

Probiotics are defined as 'live microorganisms which when administered in adequate amounts confer a health benefit on the host' [7,8]. Efficacy of probiotics on survival, 
growth, biochemical changes and energy utilization performance is immense [9]. Probiotics may be consumed either as food components or as non-food preparations. Probiotic organisms are sold mainly in fermented foods as starter organisms, and dairy products play a predominant role as carriers of probiotics. These foods are well suited to promoting the positive health impact in lactose intolerance, Urinary tract infections in woman, gut function, Traveler's diarrhea, infantile diarrhea, antibiotic associated diarrhea, helicobacter pylori gastritis, inflammatory bowel disease (IBD), irritable bowel syndrome (IBS) and colorectal cancer (CRC), immune function, infant health, atopic disease and atopic dermatitis for probiotics [7]. Health benefits of probiotics have been shown in Fig. 1 [11]. When probiotics are added to fermented foods, several factors must be considered that may influence the ability of the probiotics to survive in the product and become active when entering the consumer's gastrointestinal tract. These factors include 1) the physiologic state of the probiotic organisms added (whether the cells are from the logarithmic or the stationary growth phase), 2) the physical conditions of product storage (e.g. temperature), 3) the chemical composition of the product to which the probiotics are added (e.g. acidity, available carbohydrate content, nitrogen sources, mineral content, water activity, and oxygen content), and 4) possible interactions of the probiotics with the starter cultures (e.g. bacteriocin production, antagonism, and synergism). The probiotic bacteria used in commercial products today are mainly members of the genera Lactobacillus and Bifidobacterium. Lactobacillus species from which probiotic strains have been isolated include L. acidophilus, L. johnsonii, L. casei, L. rhamnosus, L. gasseri, and L. reuteri. Bifidobacterium strains include B. bifidum, B. longum, and B. infantis. Different yeast species of probiotics are Saccharomyces cerevisiae, Debaryomyces hansenii, Torulaspora delbrueckii, Kluyveromyces lactis, Kluyveromyces marxianus and Kluyveromyces lodderae [10].

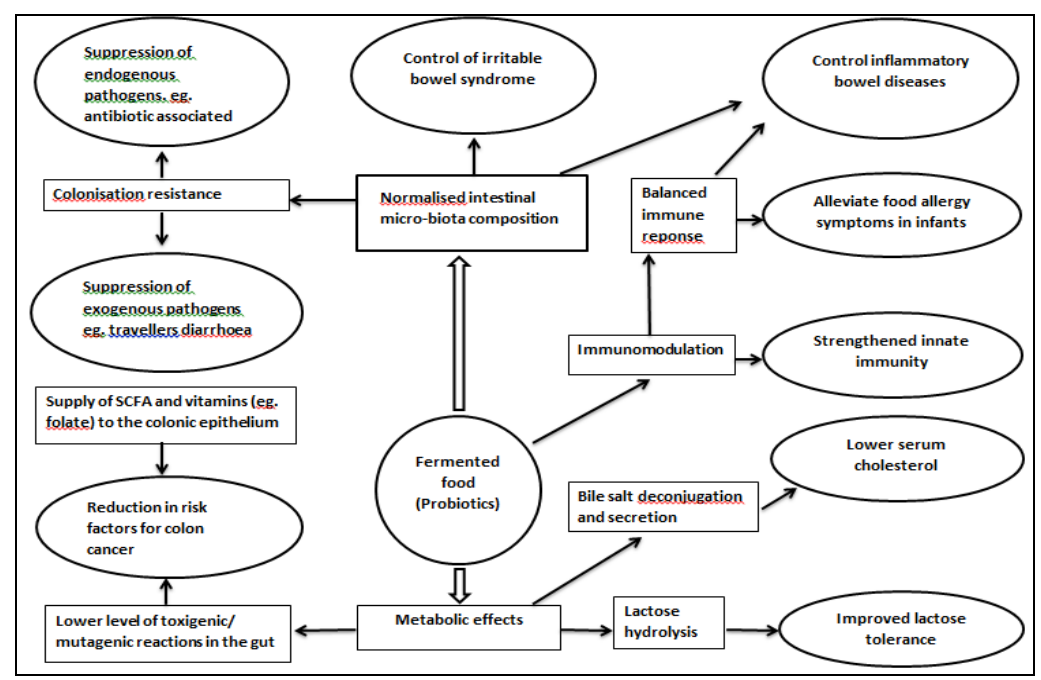

Fig. 1. Various health benefits from fermented food (probiotics) consumption [11]. 


\subsection{Preservation}

Preservation of foods by fermentation is a widely practiced from ancient time [12]. Fermentation ensures not only increased shelf life and microbiological safety of a food but also make some foods more digestible and in the case of cassava fermentation reduces toxicity of the substrate. Although many fermentation processes traditionally dependent on inoculation from a previous batch starter cultures were available for many commercial processes such as cheese manufacture thus ensuring consistency of process and product quality. It is anticipated that the contribution of the advances in lactic acid bacteria \& certain yeast research towards improvement of strains for use in food fermentation will benefit both the consumer and the producer.

\subsection{Flavor enhancement}

Fermentation makes the food palatable by enhancing its aroma and flavor. These organoleptic properties make fermented food more popular than the unfermented one in terms of consumer acceptance [13]. However, the specific mechanisms by which flavor generated are still subject to investigation.

\subsection{Improvement of nutritional quality}

Fermented foods can be more nutritious than their unfermented counterparts. This can come about in at least three different ways. Microorganisms not only are catabolic, breaking down more complex compounds, but they also are anabolic and synthesize several complex vitamins and other growth factors. The second important way in which fermented foods can be improved nutritionally has to do with the liberation of nutrients locked into plant structures and cells by indigestible materials. This is especially true in the case of certain grains and seeds. Milling process do much to release nutrients from such items by physically rupturing cellulosic and hemicellulosic structures surrounded the endosperm, which is rich in digestible carbohydrates and proteins. Crude milling, however, practiced in many less developed regions, often is inadequate to release the full nutritional value of such plant products; even after cooking; some of the entrapped nutrients may remain unavailable to the digestive process of humans. Fermentation, especially by certain bacteria, yeast and molds, breaks down indigestible coatings and cell walls both chemically and physically. A third mechanism by which fermentation can enhance nutritional value, especially of plant materials, involves enzymatic splitting of cellulose, hemicellulose, and related polymers that are not digestible by humans into simpler sugars and sugar derivatives. Cellulosic materials in fermented foods can be nutritionally improved for humans by the action of microbial enzymes [1]. A number of foods especially cereals are poor in nutritional value, and they constitute the main staple diet of the low income populations. However, lactic acid bacteria (LAB) and yeast 
fermentation has been shown to improve the nutritional value and digestibility of these foods. The acidic nature of the fermentation products enhances the activity of microbial enzymes at a temperature range of $22-25^{\circ} \mathrm{C}$ [14]. The enzymes, which include amylases, proteases, phytases and lipases, modify the primary food products through hydrolysis of polysaccharides, proteins, phytates and lipids respectively. Thus, in addition to enhancing the activity of enzymes, fermentation also reduces the levels of antinutrients such as phytic acid and tannins in food leading to increased bioavailability of minerals such as iron, protein and simple sugars.

\subsection{Alleviation of lactose intolerance}

The inability to digest lactose in lactase-deficient individuals, or milk sugar, is prevalent worldwide. Consumption of lactose by those lacking adequate levels of lactase produced in the small intestine can result in symptoms of diarrhea, bloating, abdominal pain and flatulence [15]. Milk with cells of L. acidophilus aids digestion of lactose by such persons. It has been documented that many lactose intolerant individuals are better able to consume fermented dairy foods, such as yoghurt, with fewer symptoms than the same amount of unfermented counterpart. Fermented food yoghurt was found to be helpful in the digestion of lactose because the lactic acid bacteria used to make yoghurt produce lactase and digest the lactose [16].

\subsection{Improvement of immunity system}

The immune system acts to protect the host from infectious agents and a variety of noxious agents existing in the environment [17]. In principle, the immune system has two functional divisions: the innate and the acquired. Both components involve various bloodborne factors (complement, antibodies, and cytokines) and cells. A variety of secondary plant metabolites including polyphenols produced from fermented food might also contribute to the beneficial effects. Regulat is produced by cascade fermentation with several fermentation steps involving five different strains of Lactobacillus. Polyphenols are prominent in the resulting macerate and published data have shown the antioxidative and immunemodulating potential in vitro. Several in vitro and in vivo studies have shown that polyphenols such as flavonoids have antioxidative and immunomodulatory actions. The high content of polyphenols might therefore be at responsible for the bioactive effects of Regulat [18]. The trial was to identify a suitable marker that could be used to obtain significant insight into the complex network of immune function, inflammation, and the redox state and the impact of Regulat as well as fermented foods in healthy subjects [17]. There are several studies indicating the stimulation of the host cell immunity, both innate and adaptive immunity, by $S$. cerevisiae var. boulardii in response to pathogen infections. 


\subsection{Maintenance of epithelial barrier integrity}

The intestinal and upper reproductive tract are lined by a continuous monolayer of columnar epithelial cells that is responsible for maintaining the physical and functional barrier to harmful microorganisms, such as bacteria and their products, including bacterial toxins as well as commensal organisms. The preservation of the barrier function is dependent on the intactness of apical plasma membrane on the epithelial cells as well as the intercellular tight junctions. The disruption of the tight junctions can cause increased permeability, leading to "leakiness" such that normally excluded molecules can cross the mucosal epithelium by paracellular permeation, and could lead to inflammatory conditions in the mucosa. Various pathogenic organisms have developed strategies to either infect or traverse through the epithelial cells at mucosal surfaces, as part of the strategy to establish infection in the host [19]. It has been shown that exposure of different strains of $S$. cerevisiae (human epithelial colorectal adenocarcinoma cell lines) increased the transepithelial electrical resistance (TER) across polarized monolayers of cells [18]. In another study, infection of T84 cells with enteropathogenic E. coli reduced the monolayer transepithelial resistance and distribution of tight-junction-associated protein Zonula occludens was altered, which caused disruption of epithelial barrier structure [20].

\subsection{Prevention of toxic effects of mycotoxins}

Mycotoxins are secondary metabolites produced by fungi belonging mainly to the Aspergillus, Penicillium and Fusarium genera. Agricultural products, food and animal feeds can be contaminated by these toxins and lead to various diseases in humans and livestocks [21]. Contamination of agricultural products by mycotoxins is a worldwide dilemma. The most important mycotoxins are the aflatoxins, ochratoxins, fumonisins, deoxynivalenol, zearalenone and trichothecenes [22]. Various fermented food microorganisms are able to some extent and with varied efficiency to degrade mycotoxins to less- or non-toxic products. Inhibition of mycotoxin absorption in the gastrointestinal tract is another way to prevent the toxic effects of mycotoxins. There has been increased interest in the use of mycotoxin binding agents, e.g. yeasts and yeast-derived from fermented food products, which can be added to the diet to bind mycotoxins. S. cerevisiae has the ability to bind mycotoxins [23]. The mechanism of detoxification by yeast is due to the adhesion of mycotoxins to cell-wall components.

\subsection{Bioavailability of nutrient}

Beneficial functions of probiotic microorganism like yeasts are improvement of bioavailability of minerals through the hydrolysis of phytate, folate biofortification and detoxification of mycotoxins due to surface binding capacity of the yeast cell wall. Nowadays, the products of modern yeast biotechnology form the backbone of many commercially important sectors, including foods, beverages, pharmaceuticals, industrial 
enzymes and others. S. cerevisiae, which according to EFSA (The European Food Safety Authority) has a QPS (Qualified Presumption of Safety) status [24], is the most common yeast used in food fermentation where it has shown various technological properties. Yeasts do also play a significant role in the spontaneous fermentation of many indigenous food products. A review on S. cerevisiae in African fermented foods has been provided by Jespersen [25]. However, there are other reported effects such as enrichment of foods with prebiotics as fructooligosaccharides [26], lowering of serum cholesterol [27], antioxidative properties, antimutagenic and antitumor activities [28] etc. Additional information on health significance and food safety of yeasts in foods and beverages can be obtained from Fleet and Balia [31]. There is a great interest in finding yeast strains with probiotic potential. Different yeast species such as D. hansenii, T. delbrueckii [29], K. lactis, $K$. marxianus and $K$. lodderae have shown tolerance to passage through the gastrointestinal tract or inhibition of enteropathogens [30]. However, S. boulardii is the only yeast with clinical effects and the only yeast preparation with proven probiotic efficiency in double-blind studies [31]. S. boulardii, isolated from litchi fruit in Indochina by Henri Boulard in the 1920s, is commonly used as probiotic yeast especially in the pharmaceutical industry and in a lyophilized form for prevention and treatment of diarrhoea. In a study conducted by Jespersen [25] on commercial strains of S. boulardii, it was found that the $S$. boulardii strains morphologically and physiologically could be characterized as $S$. cerevisiae.

\subsection{Folate biofortification}

Folates (vitamin B9) are the essential cofactors in the biosynthesis of nucleotides and therefore crucial for the cellular replication and growth. Plants, yeast and some bacterial species in fermented food contain the folate biosynthesis pathway and produce natural folates, but mammals lack the ability to synthesize folate and they are therefore dependent on sufficient intake from the diet [23]. S. cerevisiae is a rich dietary source of native folate and produces high levels of folate per weight [32].

Before discussing anything else the major beneficial effects of yeasts in fermented food are given in Table 1 [33].

\subsection{Biodegradation of phytate}

Fermented food has the ability to biodegrade the phytic acid. Phytic acid or phytate (myoinositol hexakisphosphate, IP6) is the primary storage form of phosphorus in mature seeds of plants and it is particularly abundant in many cereal grains, oilseeds, legumes, flours and brans. Phytate has a strong chelating capacity and forms insoluble complexes with divalent minerals of nutritional importance such as iron, zinc, calcium and magnesium. Phytases are widespread in various microorganisms including filamentous fungi, Grampositive and Gram-negative bacteria and yeasts [34]. Yeasts or yeast phytases can be applied for pre-treatment of foods to reduce the phytate contents or they can be utilized as 
food supplement in order to hydrolysis the phytate after digestion. The phytase activities of yeast during bread making for reduction of phytate content of bread have been examined [34].

Table 1. Overview of the major beneficial effects of yeasts in fermented food [33].

\begin{tabular}{|c|c|c|}
\hline Activity & Yeast species & Heath effects \\
\hline Probiotic effect & S. cerevisiae var. boulardii & $\begin{array}{l}\text { Effect on enteric bacterial } \\
\text { pathogen, maintenance of } \\
\text { epithelial barrier integrity, anti- } \\
\text { inflammatory effects, effects on } \\
\text { immune response, trophic effects } \\
\text { on intestinal mucosa, clinical } \\
\text { effects on diarrheal diseases. }\end{array}$ \\
\hline $\begin{array}{l}\text { Biodegradation } \\
\text { of } \\
\text { phytate }\end{array}$ & $\begin{array}{l}\text { S. cerevisiae; S. kluyveri; } \\
\text { Schwanniomyces castellii; D. castellii; } \\
\text { Arxula adeninivorans; } \\
\text { P. anomala; P. rhodanensis; } P . \\
\text { spartinae; } \\
\text { Cryptococcus laurentii; Rhodotorula } \\
\text { gracilis; } \\
\text { T. delbrueckii; } \text { K. lactis; } \text { C. krusei } \\
\text { (Issatchenkia orientalis) and Candida } \\
\text { spp. }\end{array}$ & $\begin{array}{l}\text { Nutritional importance, i.e., } \\
\text { bioavailability of divalent } \\
\text { minerals such as iron, zink, } \\
\text { calcium and magnesium. }\end{array}$ \\
\hline $\begin{array}{l}\text { Folate } \\
\text { biofortification }\end{array}$ & $\begin{array}{l}\text { S. cerevisiae; S. bayanus; S. paradoxus; } \\
\text { S. pastorianus; Metschnikowia } \\
\text { lochheadii; } \\
\text { D. melissophilus; D. vanrijiae var. } \\
\text { vanrijiae; } \\
\text { D. hansenii; P. philogaea; Kodamaea } \\
\text { anthophila; Wickerhamiella lipophilia; } \\
\text { C. cleridarum and C. drosophilae; C. } \\
\text { milleri and T. delbrueckii; S. exiguous } \\
\text { and C. lambica; P. anomala and C. } \\
\text { glabrata } \\
\text { K. marxianus and C. krusei (I. } \\
\text { orientalis) }\end{array}$ & $\begin{array}{l}\text { Prevention of neural tube defects } \\
\text { in the foetus, megaloblastic } \\
\text { anaemia, reduction of the risk for } \\
\text { cardiovascular disease, cancer and } \\
\text { Alzheimer's disease. }\end{array}$ \\
\hline $\begin{array}{l}\text { Degradation of } \\
\text { mycotoxins }\end{array}$ & $\begin{array}{l}\text { S. cerevisiae; Phaffia rhodozyma and } \\
\text { Xanthophyllomyces dendrorhous }\end{array}$ & Antitoxic in some degree. \\
\hline $\begin{array}{l}\text { Absorption of } \\
\text { mycotoxins }\end{array}$ & S. cerevisiae & Antitoxic. \\
\hline
\end{tabular}

\subsection{Intestinal pH balance}

A healthy large intestine (or colon) has a slightly acidic $\mathrm{pH}$, which tends to inhibit or destroy putrefactive bacteria. Putrefactive bacteria can produce foul smelling wind and are damaging to health when present in large numbers in the intestine. Naturally fermented 
foods contain active Lactobacilli bacteria that produce lactic acid, and many other beneficial bacteria and yeasts that also produce acids, which help to keep the large intestine $\mathrm{pH}$ at a healthy level. An acidic $\mathrm{pH}$ and a healthy population of friendly bacteria will inhibit the growth of undesirable bacteria, moulds, mould spores and yeasts, particularly Candida [34].

\subsection{Improvement of digestion and the digestibility of foods}

Healthy bacteria found in naturally fermented foods produce enzymes that can break down foods present in the intestines, thus making the nutrients easier absorption. Furthermore, the beneficial bacteria also produce vitamins such as the water soluble vitamin $\mathrm{B}$ and $\mathrm{C}$, making the fermented food richer in nutrients. Yoghurt is a prime example. It is easier to digest than the milk it is made from, and richer in water soluble vitamins [35].

\subsection{Protection against infection}

Gastrointestinal infections including diarrhoea result from a change in the gut microflora caused by an invading pathogen. It is suggested that viable lactic acid bacteria interfere with the colonization and subsequent proliferation of food borne pathogens, thus preventing the manifestation of infection [36]. L. bulgaricus, L. acidophilus, S. thermophilus and B. bifidum have been implicated in this effect. The beneficial effects of lactic acid bacteria and cultured milk products have also been attributed to their ability to suppress the growth of pathogens either directly or through production of antibacterial substances. Antibiotics have been reported to kill normal bacteria as well, often resulting in disruption of the bacterial flora, leading to diarrhoea and other intestinal disturbances. Replenishing the flora with normal bacteria during and after antibiotic therapy seems to minimize disruptive effects of antibiotic use. Fermented food have been reported to effective in prevention of various gastrointestinal infections [37]. There are reports of benefits for sufferers of rotavirus infection, traveler's diarrhoea \& antiobiotic induced diarrhea.

\subsection{Anticarcinogenic effect}

It has been reported that fermented food products can work against certain types of cancers. Animal studies have shown that lactic acid bacteria exert anticarcinogenic effect either by prevention of cancer initiation or by suppression of initiated cancer. Anticarcinogenic effects of yoghurt and milk fermented with L. acidophilus have been reported in mice. Different potential mechanisms by which lactic acid bacteria exert antitumor effects have been suggested such as changes in faecal enzymes thought to be involved in colon carcinogenesis, cellular uptake of mutagenic compounds, reducing the 
mutagenicity of chemical mutagens and suppression of tumors by improving immune response [38].

\subsection{Antihypertensive activity}

Casein hydrolysate, produced by an extracellular proteinase from L. helveticus (CP790) has been reported to show antihypertensive activity in rats. Two antihypertensive peptides have also been purified from sour milk fermented with L. helveticus and S. cerevisiae starter cultures. These two peptides inhibit angiotensin-converting enzyme that converts angiotensinogen I to angiotensinogen II, which is a potent vasoconstrictor [39]. It has been reported that consumption of certain lactobacilli, or products made from them, may reduce blood pressure in mildly hypertensive people.

\section{17. Lowering of serum cholesterol}

Reports indicate that fermented food products to have hypocholesteraemic effect. It is suggested that intake of large quantities of fermented milk furnish factors that impair the synthesis of cholesterol. It has been found that L. acidophilus has exhibited the ability to lower serum cholesterol levels [40]. This promotes the potential healthful aspects of dairy products fermented with L. acidophilus (or other lactic acid bacteria), since hypercholestermia is considered to be one of the major factors contributing to cardiovascular disease.

\subsection{Food security and cultural importance}

Fermentation technologies play an important role in ensuring the food security of millions of people around the world, particularly marginalized and vulnerable groups [41]. This is achieved through improved food preservation, increasing the range of raw materials that can be used to produce fermented food products and removing anti-nutritional factors to make food safe to eat. Moreover, there exist many examples of fermentation by-products which can be safely fed to nutritionally supplement livestock, thereby further strengthening the livelihood system. Well known examples include the by-products of brewing, such as "brewers grains" and dried yeast. These provide a good source of undegradable protein and water soluble vitamins, but need to be stored cool and fed within a week, or otherwise ensiled, to prolong their shelf-life (FAO, 1999) [42]. Fermentation is a cheap and energy efficient means of preserving perishable raw materials, which is accessible to even the most marginalized, landless, physically incapacitated rural, peri-urban and urban poor. Following harvest, fruit and vegetables, for example begin to deteriorate, especially in the humid tropics where the prevailing environmental conditions accelerate the process of decomposition. There are several options for preserving fresh fruit and vegetables including drying, freezing, canning and pickling, but many of these are inappropriate for use on the small scale: for example, 
small-scale canning of vegetables can have serious food safety implications given contamination with botulism (a possibility); but freezing fruit and vegetables is not economically viable at the small-scale [43]. Fermentation however, requires very little sophisticated equipment, either to undertake or subsequently store the fermented product, and has had a major impact on nutritional habits, traditions, and culture. As such, traditional fermentation still serves as a substitute for refrigeration or otherwise safekeeping of food, and is also directly utilized to make good of edible leftovers.

\section{Discussion}

There is need to educate the people on the need of consuming fermented foods for food security and safety. Safety is of paramount importance. Personal hygiene should be practiced to complement the overall benefits of fermented foods. The greatest drawback in the development of fermented food products in the developing countries that many products are produced under primitive conditions, resulting in low yield and poor quality, including short shelf-life [44]. Other problems include the lack of appeal in the presentation and marketing of the food products, as well as the fact that the processes are often laborious and time-consuming. The technology needs to be improved through research to advance its potential for food safety and nutritional value. The challenge is to ensure that technology is used to add value to such products, such as increased shelf-life, flavor and appealing packaging and labeling. Old ferments are not an efficient way of preserving the LAB probiotic organisms as poor survival has been reported in these products. Yeasts and LAB are used in preparation of human foods and beverages, where they besides having Technological functions confer different beneficial effects on human health and well-being. Among these, the most well known is the probiotic effect, which has been proven for $S$. cerevisiae and LAB species. By choosing appropriate yeast and LAB strains as starter cultures and using optimized food processing techniques, it is possible to improve the nutritional value of foods in general. They do have a more diverse enzymatic profile, appear to have a more versatile effect on the immune system, do provide protection against pathogenic bacteria and toxic compounds by surface binding and appear to be better suited for nutritional enrichment and delivery of bio-active molecules. Besides, yeast is much more robust than lactic acid bacteria which make them easier to produce and to distribute, especially in less developed areas. It is therefore encouraged that additional efforts are placed on exploring the health beneficial effects of fermented food.

\section{Conclusion}

The fermented foods offer tremendous potential for promoting health, improving nutrition and reducing the risk of various diseases worldwide. Usually, eight reasons considered as useful for fermented foods: (a) Fermented foods improve digestion, (b) fermented foods restore the proper balance of bacteria in the gut, (c) raw fermented foods are rich in 
enzymes, (d) fermented foods actually increase the vitamin content, (e) eating fermented foods help us to absorb the nutrients we are consuming. (f) fermented foods help to preserve it for longer period of time, $(\mathrm{g})$ fermented food is inexpensive and $(\mathrm{h})$ fermented food increases the flavor [45]. Advances in fermented food production, technology have led to a variety of products that suit diverse cultural tastes. Infants, children, adults and elderly can consume fermented foods for their good taste and their general nutritional value. Those with special medical needs can turn to fermented foods to provide added nutrition, soothe intestinal disorders, improve immune function and optimize gut ecology. Fermented foods show particular promise in reducing the incidence of malnutrition, lactose intolerance, diarrhea and food security. Although fermented foods are generally safe, and in the view that certain antimicrobial factors are present, lack of standardization in the methods used, the environment and the hygiene of the people that prepare them, will determine the quality of the product. As evidence of the health benefits of fermented food products mounts, and modern production makes these products available to world populations, one can anticipate that the consumption of fermented food products, will reach a new milestones.

\section{References}

1. N. N. Potter and J. H. Hotchkiss (CBS Publishers and Distributors, New Delhi, 2006) pp. 264277.

2. S. Moslehi-Jenabian, L. L. Pedersen, and L. Jespersen, Nutrients 2, 449 (2010). http://dx.doi.org/10.3390/nu2040449

3. A. Blandino, M. E. Al-Aseeri, S. S. Pandiella, D. Cantero, and C. Webb, Food Res. Intern. 36 (6), 527 (2003). http://dx.doi.org/10.1016/S0963-9969(03)00009-7

4. R. J. Jones, H. M. Hussein, M. Zagorec, G. Brightwell, and J. R. Tagg, Food Microbiol. 25 (2), 228 (2008). http://dx.doi.org/10.1016/j.fm.2007.11.001

5. J. T. M. Wouters, E. H. E. Ayad, J. Hugenholtz, and G. Smit, Intern. Dairy J. 12 (2-3), 91 (2002). http://dx.doi.org/10.1016/S0958-6946(01)00151-0

6. J. Varga, Z. Péteri, K. Tábori, J. Téren, and C. Vágvölgyi, Intern. J. Food Microbiol. 99 (3), 321 (2005). http://dx.doi.org/10.1016/j.ijfoodmicro.2004.10.034

7. K. J. Heller, Am. J. Clin. Nutr., Heller-374S-9S (2001).

8. FAO/WHO Expert Consultation Report, Evaluation of health and nutritional properties of powder milk and live lactic acid bacteria (Geneva, Switzerland, 2001).

9. C. Seenivasan, S. Radhakrishnan, T. Muralisankar, and P. S. Bhavan, J. Sci. Res. 4 (3), 729 (2012). http://dx.doi.org/10.3329/jsr.v4i3.10193

10. M. Psani and P. Kotzekidou, World J. Microbiol. Biotech. 22, 1329 (2006). http://dx.doi.org/10.1007/s11274-006-9180-y

11. E. Caplice and G. F. Fitzgerald, Intern. J. Food Microbiol. 50, 131 (1999). http://dx.doi.org/10.1016/S0168-1605(99)00082-3

12. S. Parvez, K. A. Malik, S. Ah Kang, and H.-Y. Kim, J. Appl. Microbiol. 100 (6), 1171 (2006). http://dx.doi.org/10.1111/j.1365-2672.2006.02963.x

13. A. Blandino, M. E. Al-Aseeri, S. S. Pandiella, D. Cantero, and C. Webb, Food Res. Intern. 36 (6), 527 (2003). http://dx.doi.org/10.1016/S0963-9969(03)00009-7

14. M. P. Mokoena, P. K. Chelule and N. Gqaleni, J. Food Protect. 68, 2095 (2005).

15. P. S. Panesar, R. Panesar, R. S. Singh, J. F. Kennedy, and H. Kumar, J. Chem. Tech. Biotech. 81 (4), 530 (2006). http://dx.doi.org/10.1002/jctb.1453 
16. L. Ebringer, M. Ferenčík, and J. Krajčovič, Folia Microbiol. 53 (5), 378 (2008). http://dx.doi.org/10.1007/s12223-008-0059-1

17. C. Schoen, D. Ernwiss, A. Schulz, D. Chema, J. Schweikart, D. Ernwiss, S. Schütt, and V. V. Baehr, Nutrition 25, 499 (2009). http://dx.doi.org/10.1016/j.nut.2008.10.022

18. T. D. Klingberg, U. Lesnik, N. Arneborg, P. Raspor, and L. Jespersen, FEMS Yeast Res. 8, 631 (2008). http://dx.doi.org/10.1111/j.1567-1364.2008.00365.x

19. A. Nazli, O. Chan, W. N. Dobson-Belaire, M. Ouellet, M. J. Tremblay, and S. D. Gray-Owen, Plos-Pathogens 6 (4), e1000852 (2010). http://dx.doi.org/10.1371/journal.ppat.1000852

20. D. Czerucka, S. Dahan, B. Mograbi, B. Rossi, and P. Rampal, Infect. Immun. 68, 5998 (2000). http://dx.doi.org/10.1128/IAI.68.10.5998-6004.2000

21. S. B. Hjortmo, A. M. Hellstrom, and T. A. Andlid, FEMS Yeast Res., 8, 781-787 (2008). http://dx.doi.org/10.1111/j.1567-1364.2008.00398.x

22. G. Schatzmayr, F. Zehner, M. Taubel, D. Schatzmayr, A. Klimitsch, A. P. Loibner, and E. M. Binder, Mol. Nutr. Food Res. 50, 543 (2006). http://dx.doi.org/10.1002/mnfr.200500181

23. J. F. Gregory, Adv. Food Nutr. Res. 33, 1 (1989). http://dx.doi.org/10.1016/S1043-4526(08)60126-6

24. Qualified Presumption of Safety of Micro-organisms in Food and Feed of Micro-organisms in Food and Feed, In the EFSA's 2nd Scientific Colloquium Report, European Food Safety Authority: Parma, Italy, (2005).

25. L. Jespersen, FEMS Yeast Res., 3, 191-200 (2003). http://dx.doi.org/10.1016/S1567-1356(02)00185-X

26. F. Maugeri, and S. Hernalsteens, J. Mol. Catal. B Enzym. 49, 43 (2007). http://dx.doi.org/10.1016/j.molcatb.2007.08.001

27. E. I. Psomas, D. J. Fletouris, E. Litopoulou-Tzanetaki, and N. Tzanetakis, J. Dairy Sci. 86, 3416 (2003). http://dx.doi.org/10.3168/jds.S0022-0302(03)73945-9

28. G. Kogan, M. Pajtinka, M. Babincova, E. Miadokova, P. Rauko, D. Slamenova, and T. A. Korolenko, Minireview, Neoplasma 55, 387 (2008).

29. M. Klimek, S. Wang, and A. Ogunkanmi, P. T, 34, 313 (2009).

30. H. Kumura, Y. Tanoue, M. Tsukahara, T. Tanaka, and K. Shimazaki, J. Dairy Sci. 87, 4050 (2004). http://dx.doi.org/10.3168/jds.S0022-0302(04)73546-8

31. G. H. Fleet, and R. Balia, In: Yeasts in Food and Beverages, A. Querol, and G. H. Fleet Eds.; (Springer-Verlag, Berlin, Germany, 2006) Vol. 2, Chap. 12, pp. 381-398.

http://dx.doi.org/10.1007/978-3-540-28398-0_12

32. J. D. Patring, J. A. Jastrebova, S. B. Hjortmo, T. A. Andlid, and I. M. Jagerstad, J. Agric. Food Chem. 53, 2406 (2005). http://dx.doi.org/10.1021/jf048083g

33. S. Moslehi-Jenabian, L. L. Pedersen, and L. Jespersen, Nutrients 2 (4), 449 (2010). http://dx.doi.org/10.3390/nu2040449

34. H. W. Lopez, F. Leenhardt, C. Coudray, and C. Remesy, Int. J. Food Sci. Technol. 37, 727 (2002). http://dx.doi.org/10.1046/j.1365-2621.2002.00618.x

35. HeartStar Herbs, Nutrapathic Clinic, http://www.heartstarherbs.com/Article\%20Health\%20Benefits\%20of\%20Fermented\%20Foods.pdf

36. D. N. Gandhi, In: S. S. Marwaha and J. K. Arora, Eds., Food Processing: Biotechnological Applications (Asiatech Publishers Inc., New Delhi, 2000) pp. 209-220.

37. P. S. Panesar, Food Nutrit. Sci. (JASMI) 2, 47 (2011). http://dx.doi.org/10.4236/fns.2011.21006

38. A. Hosono, T. Kashina, and T. Kada, J. Dairy Sci. 69 (9), 2237 (1986). http://dx.doi.org/10.3168/jds.S0022-0302(86)80662-2

39. M. Maeno, N. Yamamoto, and T. Takano, J. Dairy Sci. 79 (8), 1316 (1996). http://dx.doi.org/10.3168/jds.S0022-0302(96)76487-1

40. K. K. Grunewald, J. Food Sci. 47 (6), 2078 (1992). http://dx.doi.org/10.1111/j.1365-2621.1982.tb12955.x

41. E. Marshall and D. Mejia, FAO Diversification booklets 21 (2011). 


\section{Significance of Fermented Food}

42. FAO, Fermented Cereals - A Global Perspective, FAO Agricultural Services Bulletin No 138, Rome (1999).

43. W. H. Holzapfel, Int. J. Food Microbiol. 75, 197 (2002). http://dx.doi.org/10.1016/S0168-1605(01)00707-3

44. O. K. Achi, Afr. J. Biotech. 4 (5), 375 (2005).

45. A. M. Michaels, Fermented Foods: Top 8 Reasons to Eat Them, Cheeseslave (2009). http://www.cheeseslave.com/eat-fermented-foods/ (accessed on $23 \mathrm{Feb}, 2014$ ). 